\title{
Erratum to: Monitoring the implementation of the State-Regional Council agreement $03 / 02 / 2005$ as to the management of acute stroke events: a comparison of the Italian regional legislations
}

\author{
Donata Guidetti - Marco Spallazzi • Eugenia Rota • Nicola Morelli • \\ Paolo Immovilli - Danilo Toni - Marzia Baldereschi • Antonio Di Carlo • \\ Bianca M. Polizzi - Salvatore Ferro $\cdot$ Domenico Inzitari
}

Published online: 17 May 2013

(C) Springer-Verlag Italia 2013

\section{Erratum to: Neurol Sci}

DOI 10.1007/s10072-013-1306-z

Unfortunately, in the original publication, one of the co-authors' name was missed in the author group.

The correct author group is as follows:

Donata Guidetti ${ }^{1}$, Marco Spallazzi ${ }^{1}$, Eugenia Rota ${ }^{1}$, Nicola Morelli ${ }^{1}$, Paolo Immovilli ${ }^{1}$, Danilo Toni ${ }^{2}$, Marzia Baldereschi ${ }^{3}$, Antonio Di Carlo ${ }^{3}$, Bianca M. Polizzi ${ }^{4}$, Salvatore Ferro ${ }^{5}$, Domenico Inzitari ${ }^{6}$

The online version of the original article can be found under doi:10.1007/s10072-013-1306-z.

D. Guidetti $(\bowtie) \cdot$ M. Spallazzi · E. Rota · N. Morelli ·

P. Immovilli

Department of Neurology, G. da Saliceto Hospital,

Via Cantone del Cristo 40, 29121 Piacenza, Italy

e-mail: d.guidetti@ausl.pc.it

\section{Toni}

Emergency Department Stroke Unit-Sapienza,

University of Rome-Italy, Rome, Italy

M. Baldereschi · A. Di Carlo

Institute of Neurosciences, Italian-National-Research-Council,

Florence, Italy

B. M. Polizzi

Center Disease Control, Health Ministry, Rome, Italy

S. Ferro

Agenzia Sanitaria Emilia Romagna, Bologna, Italy

D. Inzitari

Department of Neurosciences and Pharmacology,

University of Florence, Florence, Italy

\section{Affiliations}

1. Department of Neurology, G. da Saliceto Hospital, Via Cantone del Cristo 40, 29121 Piacenza, Italy

2. Emergency Department Stroke Unit-Sapienza, University of Rome-Italy, Rome, Italy

3. Institute of Neurosciences, Italian-National-ResearchCouncil, Florence, Italy

4. Center Disease Control, Health Ministry, Rome, Italy

5. Agenzia Sanitaria Emilia Romagna, Bologna, Italy

6. Department of Neurosciences and Pharmacology, University of Florence, Florence, Italy

Moreover, the authors have missed to acknowledge Maria Elena Della Santa who helped in the preparation of this manuscript. The complete "Acknowledgments" section is given below:

Acknowledgments We are grateful to Rosalba Tommaso (Abruzzo), Antonio Mantea and Domenico Santomauro (Basilicata), Fabrizio De Falco and Renato Pizzuti (Campania), Domenico Consoli, Maurizio Iocco and Marisa Polerà (Calabria), Fabio Chiodo Grandi (Friuli Venezia Giulia), Paolo Giorgirossi (Lazio), Carlo Gandolfo (Liguria), Giuseppe Micieli, Monica Gattino, Giancarlo Fontana and Carlo Lucchina (Lombardia), Leandro Provinciali and Alberto DeAles (Marche), Anna Orlando (Piemonte), Daniele Orrico and Silvano Piffer (Trento), Pietro Fiore (Puglia), Maurizio Melis (Sardegna), Erminio Costanzo and Pietro Marano (Sicilia), Patrizia Nencini, Federico Posteraro, Elisa Scopetani, Antonio Di Carlo (Toscana), Stefano Ricci and Alessandro Montedori (Umbria), Edo Bottacchi and Piero Gaillaed (Valle d' Aosta), Bruno Giometto, Giuseppe Moretto and Francesco Pietrobon (Veneto) for their assistance for the correction of the imprecisions and errors made in reporting the contents of such resolutions/decrees and Maria Elena Della Santa for preparing the manuscript. 